Remarks.-In the foregoing case I had only to contend with one form of danger attending wounds of the throat-namely, hæmorrhage; on that point the rule of practice is plain; but another very serious form of danger arises, when the larynx or trachea is freely divided transversely. In this case, the following dilemma arises:- If the wound be brought together by sutures, the patient may die from accumulation of blood and mucus in the bronchial tubes and cells. If the external wound be not healed at a comparatively early period after its infliction, there is (according to $\mathrm{Mr}$. Porter) very little hope of recovery. This latter proposition is also in accordance with my own experience.

If the case be treated by position, without sutures, there is not any chance of this early healing of the wound.

I shall offer a few words on each of these points, and afterwards refer to a middle course, in which the dangers attending either of the plans to which $I$ have alluded, may be avoided. Any one who consults surgical authorities on these points, will find the line of practice recommended by one strongly condemned by another; and this is the case, not only among the great authors of the last generation, but is also true of those who are among the very latest writers on the subject. In proof of this, it is only necessary to read Mr. Stanley's paper, in the Medical Gazette of October, 1844; and Mr. M'Whinnie's, in THe LANCEx of September 5th, 1846, vol. ii. for that year, p. 267 .

First. What are our prospects in a case in which the air passages, being severely wounded, are, nevertheless, attempted to be healed by position, without sutures? It appears to me that such a case would almost necessarily terminate fatally, and such has been the fact in all the instances I have witnessed. The great mobility of the parts, in respiration and swallowing; the tendency of the lower part of the trachea or larynx to sink down, when completely divided; and the consequent irritation and congestion of the lungs; are the chief difficulties which we have to encounter.

Secondly. It has been remarked, that the patient in whom the larynx or trachea is divided, may die, if the wound be brought together by sutures, from accumulation of blood and mucus in the bronchial tubes and cells; but, as it is almost certain that the patient must die of these severe wounds, if sutures be not employed, it certainly follows that we ought to use them. Mr. M'Whinnie says that sutures are not allowable in wounds of the air passages, that they are irritating and hurtful; but Mr. Stanley refers to a successful case by Rust, of Berlin, in which sutures were introduced through separated portions of the thyroid cartilage; and my friend, Mr. Rumsey, of Gloucester, at a meeting of the Gloucestershire Medical and Surgical Association, related a case in which the larynx was completely divided through the thyro-hyoid ligament, and in which he successfully introduced sutures through the thyroid cartilage. In this case the sutures did not produce irritation, and the case did well. But again the question recurs-Is there not danger in closing the wound? It must be confessed there is, and before such a practice is attempted all hæmorrhage must be carefully restrained. It is not my intention to give an account of all the means to be used in such cases, but merely to refer to a plan which, as I mentioned before, appears calculated to remove the ill effects of each kind of treatment to which I have alluded, at the commencement of these remarks.

The treatment, then, which $I$ should adopt in a case in which the larynx or trachea has been freely divided, would be, after all hæmorrhage was perfectly stopped, and after waiting a short period to be assured on that point, to bring the parts accurately together by sutures, introduced even through the cartilages, if necessary; then, if great difficulty of breathing should arise, so as to threaten immediate asphyxia, either from derangement of the rima glottidis, or from accumulation of fluid in the bronchial tubes and cells, I should immediately adopt the suggestion thrown out by Mr. Porter, of Dublin, and open the trachea by a longitudinal incision; of course, this must not be thought of, except there appears an absolute necessity for such a step; but it is satisfactory to know, that we have the means in our power of rendering that line of treatment, which is certainly the best, free from the dangers which have hitherto been apparently connected with it. I would also strongly insist upon the necessity of preventing a drop of nourishment from passing by the mouth for a few days, and the necessity of nourishing the patient by enemata. To prove the sufficiency of this mode of conveying nourishment I would refer to a case treated in the Meath Hospital, in which Mr. Porter states, the patient was thus supported for several months, positively refus all food by the mouth.

Cheltenham, 1849.
ON THE

\section{MALIGNANCY OF THE EXANTHEMATA.}

Bx J. WELCH, Esq.y Surgeon, London.

THE appended case, illustrative of malignancy, vividly portrays its effects upon scarlatina. When we glance at the tabular register recording so large a mortality from this disease, the inference may be, that the trespass upon the columns of a journal will not be regarded as an intrusion. Each and all of the divisions of the exanthems are occasionally severally the subjects of malignancy, their peculiar feam tures depending upon the nature of the cause, and also on the power with which it has been applied; but no matter from what source, nor how varied the cause, the effects, more or less, are the same. In some, the instances are where the malignancy sweeps on with remarkable rapidity and vigour, producing such a revolution of changes, as almost to make a perfect chaos of disease, whilst in others it creeps in upon the system, and steals unobservantly along, making its presence only partly, and but feebly manifest, thus but little obscuring the disease, and offering but feeble opposition to the measures calculated to afford relief. Not so, however, with the former and more severe type, where all aspect of the original and pristine malady is lost, and which opposes and resists the welldoing of every remedy that otherwise would do good. This is weil instanced in the case to which these strictures appertain, and to which the attention is drawn. It ceases to be a matter of question, that much depends upon the health of the individual previous to the reception of the cause that was the originator of the disease, as well as upon the particular cause itself. That these may be, and are, as varied as the artificial states to which our natures are reduced, the occurrence of the one effect from so many different causes needs but little mention to confirm. The effect of this malignancy is to render more formidable the disease, and to baffle the accustomed measures of relief and cure. Another power it possesses is that of either quickly destroying life, or causing the disease to linger with slow, though powerful evidences of its virulence for some great length of time, the delay still having its termination by death. So, likewise, it retards the operation of otherwise beneficial measures, sometimes frustrating every remedy, and thus rendering a still greater magnitude to the existing evil. The malignancy, as a matter of course, is most assuredly more severe in those eruptive diseases where there is an attributable cause, than where it occurs in an exanthem spontaneously, without the presence of any well-defined os decisive one, because the very antagonism of the two causes striving to be in existence, and to produce their effects, would be to render a more serious hue to the malady in existence. It seems feasible why the exanthemata should most frequently attack the period of infancy, when we take into consideration the greater number of respirations in childhood, as well as the greater frequency of the heart's actions, the greater tenuity of their structures, and the activity and energy which these recent tissues assume. We may well infer that intactile causes, in the shape and name of miasms, should have some influence upon them. Take early, and compare it with middle or later life, the quickened action of the heart, and frequent respiration in the one, with the abated pulsation and slow and settled motion of the breathing in the other, supposing, too, the same cause besetting the two extremes, we find it exerting a twofold, if not greater power, and that, too, on the weaker body; hence the inference, why it attacks the period of childhood. The miasms are borne on and along through the system, becoming inherent there, and giving a vitality to disease. In many instances, the exuptions which form the characteristic and distinguishing features of these maladies, and the presence of which suffices, with but little further inquiry, to denote what exanthem it may be, often want that decisive token, so that reference has to be made to other concomitant symptoms before one can positively state what is that particular disease. Now although this feature is almost invariably wanting in cases where there is a shade of malignancy, or where there is a likelihood of its making its presence known; yet, be it observed, instances are recorded, where, without any malignancy whatever, the eruption has been wanting; but premising all this, it is a fact without question, that where there are signs of malignancy, the eruption has been either evasive or wanting. The very fact of the eruption retroceding, gives additional alarm to the disease, and forewarns the approach of more powerful and more to be alarmed-at symptoms. Now the absence of this eruption has resolved itself into a quastio vexata with medigal men, as to whether that non-eruption was dependent upon the want of power of the system at the times 
or to any peculiar feature of the mephitic agent. The fact, however, is not lessened from the different views entertained on this point. Neither does the non-knowledge of the causes to establish a fact, form, in this instance, any obstacle or impediment to a cure.

Whenever an exanthem, or, in fact, any other disease, is about to assume a malignant form, as a rule, the distinguishing feature of the complaint is sure almost to be wanting; and this forewarning token is of some import in awakening the attention, and directing a divergence from the measures otherwise inculcated and advised for that particular complaint If it were not for this contra-indication, we should be blindly opposing a disease which, from the great change, calls for, and requires, totally opposite measures of relief; and $I$ have no doubt but that many of the fatal cases recorded arise from the want of observance of this unnoticed indication. Vigorous and energetic measures must yield to those that are bland and soothing. Yet, with all this, the mind must be ever active and ready to combat with and check that symptom which is the most antagonistic and powerful. In all cases of fatal termination, whether death has taken place rapidly or in a lingering manner, the prostration that supervenes, and the complete want of balance of the nervous system, indicate clearly that the heart's power has been overcome and destroyed by the powerful sympathy inherent in this, and existing between all the other organs of the body, whose function has been in any way interfered with. And death always takes place from this self-same cause. In severe cases of malignancy, and, as will be seen from the appended case, corroborative of what follows, violent inflammatory swellings, which are sure almost to suppurate, form round one or more, most frequently many, of the joints, and this, too, totally regardless of situation or size. Why they should form their resting-places upon and near these articular movements it is somewhat difficult to divine. Unless, perhaps, the circulatory fluid in the regions of joints has to pass through more dense and unyielding structures, which compress the sides of the vessels, made distended by the globular and congestive state of the bloed, and which, owing to the excited condition of the system, will not so readily allow the blood and its vessels to be transmitted through these structures, and so, from the congestion, inflammation and its results follow-premising all this, that these ulcerations do form, which, not unfrequently, is an undisputed fact. The suppurating fluid portrays well its vitiated character by its tenuity and acrimony, although it does not follow from this that the purulent discharge should be great, for it may be in quantity either large or small. That it exerts a corrosive influence is obvious from the carious state which the circumjacent bones are liable to, and become. Supposing the disease to have reached this stage of malignancy, and that its further progress became arrested, and that all the chances of danger were removed, although, most unquestionably, when the disease has reached thus far, death seems almost inevitable, yet where recovery has taken place, the partially anchylosed state to which the joints have become reduced, for ever show the virulence to which they were at one time subjected, and which seldom or ever are lost sight of, or become removed from the system.

There is no doubt that a scrofulous state of system is favourable for, and always co-existent with, the ulcerations, where they affect the joints; even if it were the nature of the malignancy alone to attack them, it is beyond a question that a scrofulous state would make those very ulcerations more vigorous and active. It ceases, indeed, to be a matter of opinion-it has resolved itself into a fact-that these ulcerative tokens do assume a scrofulous hue. And as such must we regard them. One would fancy, that with all this state of things-with the active diarrhoea, the inflamed swellings, the enlarged glands, the extensive ulcerations \&c., that there would be the greatest possible mental anguish and suffering: such, however, seems not to be the case. The sensorium has become overpowered from the rapidity of the primary symptoms and the intensity of their character.

It is too often the case with malignant diseases, that there will be one prominent symptom throughout, which will retard their well-doing, and most effectually resist the employment of a series of the most beneficial measures. Thus it frequently runs its course from the commencement of the disease to its termination, as in the illustrative case that follows, where, notwithstanding every remed $y$, the diarrhcea remained unchecked. In some instances of eruptive fevers, and where a retrocession of the eruption has taken place, I have observed occasional faint indications of its return, as if the disease, despite the in visible power and cause of the malignancy, was striving to pursue the eyen tenour of its way. Not unfrequently these vacillations were the forerunners of symptoms more malignant than ever. When an exanthem becomes malignant the whole system is affected, and its virulence displays itself by making. one of the symptoms most prominent; sometimes the intensity of one yields to that of another, and again to another, thus pursuing a course from organ to organ, and tissue to tissue regardless of structure, form, appearance, situation, or size.

The following case, which has of late occurred to me in this densely populous neighbourhood, I select as one out of some few which best portrays the effects of malignancy.

\section{Case of Malignant Scarlatina.}

F. B. F-, aged eleven months, on the 14th of April, 1848, became attacked with an eruption (which, however, soon became evanescent) presenting the peculiar redness indicative of scarlatina. The retrocession of the eruption was followed by a diarrhœa of a most profuse character, resisting the effects of numerous astringent remedies. When I first saw the child, which was not until the 21st, he was suffering from a series of fits, attended with tremors and convulsive movements of the whole of the members of the body which continued for lengthened periods, at irregular intervals, throughout the day, the paroxysms being accompanied with hemiplegia of the right side of the body, with a retraction of the mouth to that side. Partial strabismus also evinced itself on. these occasions. In the intermissions of the paroxysms, the countenance was free from any expression of pain, which was remarkably placid, but its tranquil aspect would often change. for one of seemingly great anguish. The heat of the body was natural, the pulse rapid and weak; the tongue was morbidly red, with congested papillæ; the fauces were but little inflamed, whilst the respiratory powers were sometimes greatly depressed, and at others but little affected. There was also a. glassy and sunken state of the eyes.

Ranging from the 21st to the 26th, many of the symptoms above became more formidable, whilst also there were accessions of others equally so. Sordes appeared on the lips and gums, of a most offensive character, and pustules formed on the surfaces of the tarsus, and metatarsus, and inner side of the right knee-joint, whilst those on the feet ulcerated, and towards a later stage of the disease extended even to the bones subjacent, presenting a gangrenous aspect, with a peculiar foetid emanation. That near the knee-joint assumed alf the characteristics of a state of phlegmon. The parotid and chain of cervical glands took on an enlargement; the former was of unusual magnitude and intensity, and acted even as a barrier to the head, being turned in that direction. This also was on the right side. The right eyelid also became affected with ptosis, and this feature was rendered singular by the appearing and disappearing on every alternate day of this symptom. The alvine secretions were always of great magnitude, and had a most peculiar viscid glutinous appearance. So noisome was the effluvia from this case, that the room was not only replete with it, but for some long time afterwards retained evidences of its previous existence. Extending to the 29th, the symptoms became more urgent. The prostration which had been great all through was now exceedingly great; the diarrhœa remained unchecked whilst, throughout, the child displayed remarkable avidity for nourishment, and this was the effort of nature to compensate for the excessive loss by purging. On the evening of the $29 t h$, the tremulous motions became constant, the eye seemed more sunken, and the previous moans had settled down into an occasional sigh; on the following morning, the expectant result of death ensued.

Post-mortem appearances, forty-eight hours afterwards.-On removing the skull-cap, which was tenaciously adherent to the dura mater beneath, the vessels ramifying on the surface of the brain were congested, though not to any very great extent, whilst over the cerebral convolutions, an effusion had taken place which was of some quantity at the base, especially around the medulla oblongata, which extended into the spinal canal. The lateral ventricles were also full of this fluid, which, on slicing the brain, followed every incision of the knife, coursing as it did from the separate cavities one to another. The pleural cavities also contained some fluid of a sero-sanguineous character. The lower lobes of both lungs were hepatized, the remains of some former inflammation being evident in those structures. The stomach was remarkably thickened; instead of its smooth, white, slimy colour, it presented a dusky whiteness, and a pulpy sensation to the touch, which resisted, however, the pressure of the finger; a thickened, grumous fluid was contained therein, whilst its aspect, like the exterior, was pale and exsanguined. There was no congestive appearanoe on iț surface. The gall-bladdex 
was engorged, and its tinge was imparted to it and the adjoining structures. The large intestines were clogged with this viscid, glutinous secretion, which hitherto had marked the excretions, and they were replete with excrementitious matter; on cleansing their interior, there was no congestive or ulcerative sign whatever. A vivid redness, but no ulceration, was apparent in the fauces, and the tonsils were increased a little in size. The remaining viscera call for no further comment.

Post-mortems, however, throw but little light on these malignant diseases, notwithstanding a minute investigation into the appearances of the organs furnished by the fatal ending of the above case, there was no proof of organic lesion, but more of what has been termed the lesion of functionthis depending upon the vitiated condition to which the organs have become subservient from the mephitic agent (supposing it to have been the cause) floating in the blood.

The treatment which such cases require must be obvious, their most prominent features must be lessened by counteracting remedies, and the great state of depression invariably attendant in all malignancies, meet with agents calculated to check the advancement of the disease, and restore, by their tonicity, the disordered functions and diseased parts to health. In all stich cases, the milder the remedies, the more beneficial will be the result; provided the inherent power of the system be not overcome, the effects of the morbific agent will be somewhat retarded, and the disease will thereby be prevented from assuming a more serious or malignant form; for when we consider the train of evils that may ensue from any of the malignant exanthems, it behoves us not to disregard any of the measures because they are mild, and offered in opposition to a vigorous disease, when we know that they are best calculated to afford relief, and subsequently, it is to be hoped, a cure. Variola more often than scarlatina, and this latter more frequently than rubeola, are the subjects of malignancy, and the virulence and danger of such maladies range accordingly proportionately. But then it is the nature of these diseases to be thus proportionally severe, and successively to become affected, and more the subjects of malignancy. When. ever they become so, they always earlier or later assume the typhoid type, and this not unfrequently at an early stage of the disease. A generous diet, with free ventilation and soothing remedies, are the means most calculated to ensure a cure. The chlorate of potash, so vaunted a remedy in these affections, does not merit the qualifications bestowed upon it by some; in many instances it has appeared inert, and I have found equal benefit, and oftentimes more, in some cases, from other remedies of less reputed worth. That such diseases should require more than a passing glance, the frequent occurrences of fatal terminations clearly prove.

Church-street, Shoreditch, May, 1849.

\section{ON THE TREATMENT OF SOME CUTANEOUS DISEASES.}

To the Editor of The LANCET.

Sir,-In a review of Mr. Hunt's work on "Diseases of the Skin," which recently appeared in THE LANCET, you expressed a hope that other members of the profession would take up the subject, and test, by experience, the soundness of the views which were therein advanced: I therefore forward a selection of cases which have been treated on the principles proposed by Mr. Hunt.--I am, Sir, your obedient servant,

SaMuel Grifrith,

Late House-Physician to King's College Psoriasis.

R. B - aged nine, is a native of Bow, where he has usually resided. His general health has always been good. About twelve months since, in falling, he abraded the skin of the left knee; and from the constant irritation of his trousers, the wound became a large, thongh superficial sore. Two months after this he observed white scales form over the not quite healed wound; and at the same time an eruption of like character appeared on the right knee, elbows, forearms, and trunk. He has for some time been using ointment with, as he thinks, slight benefit.

Dec. 31st, 1846. At present he is a fine, healthy-looking lad, with a florid complexion. There are several large, irregular patches on the knees and elbows, and smaller ones scattered over every part of the body, excepting the face; they are covered with numerous shining, silvery scales; the edges are raised and irregular; there is no itching or uneasi- ness; bowels free; tongue clean. Ordered, nitro-muriatic acid, ten minims; infusion of cinchona bark, a pint. Mix. An ounce to be taken three times a day.

He continued taking this medicine up to the 20th of January, when there was an improvement in some of the patches; a few of the smaller ones had healed. He was directed to continue this medicine, and apply the nitrate of mercury ointment.

Feb. 10th, 1847.- Many of the patches have disappeared, only a slight brown stain; the others are smaller, and less scaly. Repeat the remedies.

26th.-The eruption, which had nearly passed away, is now returning in many places. From this period, up to May 29 th, various external applications were used, as the nitrate of silver, tincture of iodine, \&c. Liquor potassæ, and a compound of arsenic-with-mercury, (not to salivation,) were also given internally, but without benefit, for any temporary amendment that might have taken place was soon followed by an increase of the disease.

May 29th.-At present there are numerous small patches about the trunk; others on the arms, spreading, as it were, from the elbow-joints on either surface; the largest are scattered on the anterior part of the knees and legs; the patches are much raised, scaly, and itchy, which induces the boy to scratch, when an ichorous fluid is discharged, forming a hard cake over several of them. The other functions appear healthy. Ordered, Fowler's solution of arsenic, a drachm; distilled water, seven drachms. Mix. Forty minims to be taken, in water, thrice daily.

June 19th.-A marked change in the character of the eruption has taken place; it is paler, less scaly, and there is a total absence of the irritation which so much annoyed him a fortnight since. No fresh patches have appeared, nor are there any unfavourable symptoms from the use of the arsenic; the only indications of the system being under its influence are the amendment of the disordor, and an almost imperceptible inflammation of the conjunctiva.

He continued the same treatment up to July 15 th, when all trace of the disease, with the exception of a slight discoloration of the skin, had disappeared.

Feb. 2nd, 1848. - No return of the eruption; the skin is quite free from spots or roughness.

March 30th.-Two small spots having shown themselves"on the right knee, he recommenced taking the drops a fortnight since. The spots are now almost gone. To continue the arsenic, in four-minim doses, for a month longer.

Feb. 1849. - The boy is well, and entirely free from his former complaint, of which he has had no return.

\section{Lepra.}

James P_, aged twelve, is a stout, healthy-looking. boy, somewhat predisposed to scrofula, but has generally enjoyed excellent health; his parents and brothers are free from eruptive disorder. About two months before consulting me, he perceived an eruption, which, commencing at the elbows, soon spread over the backs of both arms. Occasional aperients, and other medicines, were exhibited, but the disease continued spreading. It first appeared as small clusters of papulæ, each of which became covered with a scale; these subsiding, others sprang up around them, and formed the circular, scaly patches, with elevated borders, characteristic of lepra vulgaris. Many of these have now become confluent, presenting the ordinary appearance of psoriasis; while others still retain the circular form of lepra. The eruption extends over both arms, neck, and trunk.

Dec. 28 th, 1846.- There being nothing to contraindicate its use, Fowler's solution of arsenic was given, in doses of five minims, with his meals, three times a day.

Jan. 6 th, 1847.-The psoriasis continues about the same, but the body is nearly covered with a papular eruption, (lichen sifnplex.) The itching is troublesome, especially in the night, preventing sleep. The conjunctiva is affected. Continue the arenic.

16th.-The lichen has died away, leaving the skin coated with fine scurf. The lepra is fading, no fresh patches have appeared; the sub-maxillary glands are swollen and tender, and he complains of weakness of the eyes. The conjunctiva being more injected than is consistent with the proper action of the medicine, the dose was reduced to four minims.

30th.-The eruption is fast fading; the swelling of the glands has subsided, but the conjunctiva remains affected. The general health continues very good. Skin free from the lichenous scurf.

Feb. 15.-The lepra is quite gone, but has left the usual brown stains. The arsenic was continued to the end of March. 